\title{
ENERGY SAVING BY FIRMS: DECISION-MAKING, BARRIERS AND Policies
}

\author{
Henri L.F. de Groot, Erik T. Verhoef, and Peter Nijkamp ${ }^{1}$ \\ Department of Spatial Economics \\ Vrije Universiteit, Amsterdam \\ De Boelelaan 1105 \\ $1081 \mathrm{HV}$ Amsterdam \\ The Netherlands \\ E-mail: hgroot@econ.vu.nl
}

April 1999

\begin{abstract}
.
Promoting investments in energy saving technologies is an important means for achieving environmental goals. Unfortunately, the empirical evidence on success conditions of policies is scarce. Based on a survey among Dutch firms, this paper sets out to identify the factors that determine the investment behaviour of firms, their attitude towards various types of energy policy, and their responsiveness to changes in environmental policy in the Netherlands. On the basis of discrete choice models, this paper aims to investigate empirically whether (and how) these strategic features vary over firm characteristics and over sectors.
\end{abstract}

JEL-codes: D20, Q40, Q48

Key-words: energy saving, investment behaviour, environmental policy

1 This research was performed by the Free University of Amsterdam in cooperation with the University of Utrecht. It was carried out within the Dutch NRP-II project on 'Policy Instruments for Energy Efficiency Improvement', nr. 953215. Financial support by the Dutch Scientific Organization (NWO) is gratefully acknowledged. We also would like to thank Carolien Rodenburg for research assistance. Peter Nijkamp and Erik Verhoef are affiliated to the Tinbergen Institute. 


\section{Introduction}

Environmental quality and resource management has become a prominent challenge in a modern economy. The complexity involved has prompted a series of diverse policy initiatives, ranging from market oriented instruments (e.g., Pigouvian taxes, tradeable permits) to command and control measures. The pros and cons of such policies have been extensively mapped out in the literature (see for a general overview Tietenberg et al., 1999). In practice, many policy initiatives were flawed by much uncertainty (see e.g. Roberts and Spence, 1976; Adar and Griffin, 1976), so that a clear choice for price-based instruments - as opposed to quantity-based instruments - could no longer be sustained. Consequently, we have seen a formidable variation - over time and among countries - in the application of policy instruments and measures. This also holds for a country with a traditionally strict environmental policy, the Netherlands.

With varying degrees of priority, environmental problems are still high on the Dutch policy agenda. In recent years, Dutch environmental policy has been relatively successful, at least in the reduction of emissions of some pollutants. Despite a strong economic growth performance, many emissions of pollutants have been reduced. This improvement is to a large extent the result of a more intensive use of environmentally-friendly technologies, the adoption of which was stimulated by the imposition of clear policy objectives, task requirements, and voluntary agreements. Despite these improvements, several serious problems still remain. The most pressing problems in the Dutch situation are associated with climate change, noise, and eutrofication. Additional policies are still required to reach the targets that have been set in the so called NMP3 (the most recent Dutch national environmental plan).

In this plan, the Dutch government opts for more intensive use of voluntary agreements, but also for using and exploiting market-based incentive mechanisms. The general goal here is to better reflect environmental decay in prices so as to encourage behavioural changes. Fiscal measures should result in product prices that more properly mirror the (marginal) social costs associated with the use of energy. These additional measures should result in adjustments in producers' and consumers' behaviour, product and process innovations, and a lower use of scarce environmental resources. In order to assess and judge 
the desirability, the effectiveness and the acceptability of such proposed policy changes, it is of critical importance to obtain clear empirical insights into the way investment decisions in general, and energy use in particular, emerge within firms, how these decisions can be influenced by governance strategies, how firms would respond to various possible policies, and how they judge the feasibility and acceptability of these measures. Against this background, the present paper will address the potentials and impediments of energy-saving strategies among firms by a series of empirical results originating from the analysis of a survey among Dutch firms, dedicated to success conditions for energy savings.

Detailed systematic empirical studies at a sectoral or firm level are rather scarce in the Netherlands. Some years ago, for instance Velthuijsen (1993) and Gillissen et al. (1995) performed also a questionnaire among firms, in which they also focussed on energy use and related investments. Our research broadens their scope in that we do not only focus on investment behaviour, but also on the stated response to and attitudes towards a set of specified policy instruments. Our new data set allows in addition for a more detailed analysis of the role of various types of uncertainty in investment decisions, which, according to investment theories as developed by, for example, Dixit and Pindyck (1994), may be a major explanatory factor for seemingly irrationally high revealed internal discount rates in investment evaluation (see, for example, Johnson (1994)). It thereby aims at broadening our understanding of decision-making on energy use in companies and energy gaps as have been widely documented in the literature. The 'background variables' in our study, however, that are necessary for statistical analysis, are deliberately largely similar to those in the above mentioned studies.

The survey was held in the spring of 1998 among Dutch firms. These firms were randomly selected from the register of the Chambers of Commerce and were more or less equally distributed among the most energy-intensive sectors of the Dutch economy, namely the chemical industry, basic metals, metals and machinery, food, paper, horticulture, construction materials, and textiles. The extensive survey contained a detailed set of questions about energy use, investments, the firm's competitive position in the market, internal decision making, its attitude towards and adoption of energy saving technologies, as well as its attitude towards and responsiveness to Dutch environmental policy. The statistical results also 
incorporate a body of empirical knowledge on the expected effects and acceptability of energy policies, two major determinants for the viability of environmental and energy policies.

In this paper we will present the results of the above survey and investigate how investment behaviour, attitudes and responsiveness towards economic policy, as well as barriers to the adoption of readily available energy efficient technologies, vary over sectors and with firm characteristics. Our analysis will be presented in five separate sections. Section 2 discusses the survey and gives a description of the firms and sectors included in the sample. Section 3 considers the investment behaviour of firms, along with the perceived barriers to investing in cost effective energy saving technologies (in the context of the so-called energy efficiency paradox). In Section 4, attention is shifted to how firms stated to react in response to an increase in energy taxes on a national level (with no rebatements). Section 5 discusses next the attitudes towards environmental policies in the Netherlands. Section 6, finally, contains an evaluation and presents the policy conclusions emerging from our empirical analysis.

\section{The survey}

The survey resulted in a data set of 135 companies (i.e. plant locations) established in the Netherlands. Firms in nine sectors of the economy were randomly selected, and received a 15 page survey in May 1998. Confidentiality was guaranteed. The survey asked firms about their characteristics (size, profitability, residential sector to which it belongs, number of employees, export share, etc), their energy use (in monetary and volumetric equivalents), their investments (in general, and purely aimed at energy efficiency improvements), their position in the market (strength of competition, location of competitors, how the firm compares to competitors in terms of size, sales, profitability, etc), their focus in policy making (importance of short- and long-run profitability, reduction of labour and energy costs, improvement of environmental image, increase in sales, etc.), their expectations about the development of costs of inputs, their knowledge, implementation and use of energy saving technologies, their attitudes towards and willingness to accept energy policies of various types (voluntary agreement, taxes at national and international level, subsidies, standards, etc.), and their R\&D behaviour 
(expenditures, degree of cooperation and outsourcing, size of R\&D staff, criteria for project selection, etc.). Firms were divided over the following nine sectors: the chemical industry, basic metals, metals, machinery, food, paper, horticulture, construction materials, and textiles. In the remainder of this paper, we will distinguish 7 , more aggregate sectors, namely the chemical industry (18\% of the sample; further labelled as CHEM), basic metals (10\%; BASEMET), metal products (11\%; MET), food (14\%; FOOD), paper (7 \%; PAPER), horticulture (24\%; HORT), and the rest (REST) consisting out of machinery, construction materials and textiles. ${ }^{2}$

Table 1 summarises relevant information on some key characteristics of the firms in the various sectors under investigation. The categories according to which firms are distinguished are their share of energy costs in total sales, their investments as a share of sales, their profits as a share of sales, the number of employees, their perception of competition (ranging from limited (score 1) to intensive (score 3)), and the location of their competitors (ranging from mainly in the Netherlands (score 1) to virtually all abroad (score 4)). A first statistical experiment concerned the explanation of the above set of firm characteristics from a set of sectoral dummies. Statistical significance in the table indicates that a particular firm characteristic deviates significantly from the sample average in the industry under

2 The overall response rate was $4.2 \%$. Response rates per sector differed considerably. They ranged from $1.46 \%$ in the textile industry to $8.73 \%$ in horticulture. Although admittedly low, such a response rate is common and acceptable for this kind of extensive survey research (compare, e.g., Vicini (1998)). A first rough analysis of the data gives no reason for suspecting serious selection biasses in the sample. Furthermore, for the ultimate goal for which the survey was held, namely studying how decision making, barriers and attitude towards policy vary over different firms and sectors, we suspect no serious effects of a potential selection bias. Clearly, some caution is needed when generalizing the results. Data on size in terms of employees, energy intensity, and profitability were confronted with available evidence from the Dutch Statistical Bureau (CBS) in 'De Nederlandse Energiehuishouding, Deel 2' (Table 9). Although the data are not fully comparable (our measure of size is the number of people working in a firm, independent of whether they work part-time or not, and the CBS reports gross returns before taxation while we have data on net profitability), they suffice to express some confidence in the representativeness of our data set. The means reported in Table 1 do not differ significantly from the reported sectoral averages by the CBS for energy intensity and size (at a significance level of $5 \%$ ). Also, the relative order of magnitude of these variables according to the CBS is comparable to the order of magnitude in our sample. From the respondents within the firms, 75\% was associated with energy, investment and/or technological management. Only $11 \%$ of the firms that responded had an energy coordinator, from which we may conclude that firms which are already explicitly working on their energy management are not overrepresented in the sample (compare Gillissen et al., 1995; Table 6.3). More detailed information on this analysis is available upon request from the authors. 
investigation. The parameters reported in the table were estimated using OLS, where the independent variable was the deviation of a firm's score from the sample average, and the independent variables were all sectoral dummies (note that no constant was used, as deviations from the sample average were considered). A comparable procedure will be used below, when the variation over sectors is considered. The sum of the sample average and the sector-specific effect yields the average score of a specific variable in that particular industry.

Table 1. Firm characteristics versus sectors: OLS

\begin{tabular}{l|ccccccccc}
\hline FIRM CHAR. & $\begin{array}{c}\text { Sample } \\
\text { average }\end{array}$ & CHEM & BASEMET & MET & FOOD & PAPER & HORT & REST \\
\hline OBSERV & 135 & 24 & 13 & 15 & 19 & 10 & 33 & 21 \\
ENQ & 0.10 & -0.01 & -0.06 & -0.08 & -0.07 & -0.06 & $+0.14^{* * * *}$ & -0.08 \\
INQ & 0.11 & -0.04 & -0.02 & -0.07 & -0.06 & +0.09 & $+0.09^{* * *}$ & -0.05 \\
PRQ & 0.03 & +0.02 & +0.05 & +0.03 & +0.08 & +0.08 & -0.17 & +0.10 \\
LABOUR & 279 & +285 & $+758^{* *}$ & -233 & +111 & -218 & -253 & -227 \\
LLABOUR & 3.16 & $+1.67^{* * * *}$ & $+1.50^{* * *}$ & -0.19 & -0.08 & -0.21 & $-0.95^{* * *}$ & $-1.05^{* * *}$ \\
COMP & 2.42 & +0.13 & +0.17 & $-0.28^{*}$ & -0.05 & -0.12 & $+0.21^{*}$ & $-0.30^{* *}$ \\
COMPIN & 2.23 & $+0.99^{* * * *}$ & $+0.85^{* * *}$ & -0.23 & $-0.87^{* * *}$ & +0.33 & -0.16 & $-0.70^{* *}$ \\
\hline
\end{tabular}

*/**/***: significant at the 0.1/0.05/0.01 level (two-sided t-test) in OLS regression with sectoral dummies

\section{VARIABLE DESCRIPTIONS}

OBSERV Number of observations;

ENQ Energy intensity (expenditures on energy as percentage of sales);

INQ Investment ratio in 1997 (total investments as percentage of sales);

PRQ Profit ratio (total profits as percentage of sales);

LABOUR Number of employees (full time and part time);

LLABOUR Log of number of employees;

COMP Degree of competition on sales market (1=limited, 2=average, and 3=strong);

COMPIN Location of competitors ( $1=$ mainly in Netherlands, $2=$ less than $50 \%$ abroad, $3=$ more than $50 \%$ abroad, 4=virtually all abroad).

From this table, it is evident that horticulture is the most energy intensive sector with relatively small firms, and invests - relative to profits - significantly more than firms in other sectors. In addition, competitive forces in horticulture are perceived as strong (especially on the national market). The chemical sector and the sector producing basic metals can both be characterised by larger-sized firms and the fact that most of their competitors are located abroad. In contrast, firms in the food sector and machinery, construction materials, and textiles indicate that most of their competitors are located in the Netherlands.

The column variables reported in Table 1, referred to as 'firm characteristics' in the sequel, appear to be often strongly correlated. Especially the degree of competition and the 
location of competitors are strongly positively correlated, while the profit rate and the energy intensity are strongly negatively correlated. This may create statistical problems in the multiple regression estimation of models, due to the presence of multicollinearity. We will evade this problem in the remainder of this paper by restricting the reported results to simple regressions. The focus is therefore on the overall impact, not the marginal effect, of these variables on the response variables studied. In the same vein, we will report separate estimations of the effect of (the full set of) sector dummies on the response variables. In the context of the type of questions studied, the advantage of this approach is that the 'full' effect of the independents on the dependants is determined. The interpretation of marginal effects is probably less relevant from a policy perspective, in particular because the independents considered simply are correlated in reality. The estimation results obtained with multiple regressions would cloud these correlations. Moreover, it should of course be acknowledged that the data set is simply too small to allow for multiple regressions taking all possibly relevant variables on board, in particular if more advanced statistical techniques such as 2SLS were used.

\section{Investment behaviour and barriers to investment}

We will now turn to the stimuli and barriers concerning firm investments. In one of the central parts of the survey, firms were asked about their investment behaviour, and the factors that they perceived as preventing them from investing in energy saving technologies that were considered, but that were nevertheless not (yet) adopted.

The share of total investments that is spent on technologies that are purely aimed at energy saving is low at first sight (on average slightly below $10 \%$ ), but at the same time, these shares do not significantly differ from the share of energy costs in total sales. Most firms in the survey indicate that energy efficiency is an important factor in their investment decisions. Furthermore, Figure 1 reveals that, at least in the firms' own perception, there is no systematic under- or overestimation of the relative importance of energy efficiency in overall investment decisions. It is therefore possible that substantial further energy saving may still take place by incorporating energy efficiency as a decision variable when installing new machines or buildings. This conclusion was further confirmed by asking firms about their future investment 
behaviour. It turned out that most firms expect the total investment budget to remain largely constant (or to increase slightly). This also holds, but to a lesser extent, for investments purely aimed at increasing energy efficiency. However, the importance of energy efficiency in investment decisions is expected to increase (albeit slightly). One may therefore conclude that, according to the respondents, energy efficiency becomes an integrated and important aspect of the overall evaluation of investment opportunities (we will return to this below when we discuss barriers to investments).

\section{< Insert Figure 1 around here >}

Before proper investment decisions can be made, adequate knowledge is required on the various alternative investment opportunities. Lack of information is a principal source of market failures that can account for sub-optimal investment behaviour. To obtain knowledge on suitable technologies, most firms turn out to rely on specialist publications. Also direct contacts with suppliers, the industrial board and colleagues appear to be intensively used to gather information. Formal organisations like the government and NOVEM (the Dutch organisation of energy suppliers) play only a minor role in providing firms with information. As far as perceived knowledge is concerned, about $30 \%$ of the firms indicate that they are not, or only to a minor extent, aware of existing new technologies that are not yet being used in practice by any firm. Of course, a smaller percentage of $20 \%$ have only limited knowledge on technologies that are currently used by other firms. These results suggest that future policy can improve upon the situation by providing firms with relevant information on investment possibilities in energy saving technologies. The public nature of information provides of course good arguments for such a governmental role in providing and disseminating information.

It is often argued that small firms are in a particular disadvantageous position in obtaining strategic information on new and already existing technologies. In order to obtain information on whether the perceived knowledge varies over sectors and over firms with particular characteristics, we have regressed the perceived knowledge on sector dummies and firm characteristics. The results are shown in Tables $2 \mathrm{a}$ and $2 \mathrm{~b}$. In Table $2 \mathrm{~b}$, we report simple 
ordered probit estimates. ${ }^{3}$ As already mentioned at the end of Section 2, we restrict our attention to simple estimates, as the explanatory variables are characterised by collinearity.

Table 2a. Perceived knowledge on available technologies: sectors, OLS

\begin{tabular}{|c|c|c|c|c|c|c|c|c|}
\hline KNOWLEDGE & $\begin{array}{l}\text { Sample } \\
\text { average }\end{array}$ & CHEM & BASEMET & $M E T$ & FOOD & PAPER & HORT & REST \\
\hline Know_exist & 3.18 & +0.28 & -0.35 & $-0.58^{* *}$ & +0.01 & +0.04 & -0.32 & -0.07 \\
\hline Know_new & 2.79 & $+0.33^{*}$ & -0.04 & -0.39 & $-0.38^{*}$ & +0.01 & +0.15 & +0.01 \\
\hline
\end{tabular}

$* / * * / * * *$ indicates significance at the $0.1 / 0.05 / 0.01$ level (two-sided t-test) in OLS regression

VARIABLE DESCRIPTION

Know_exist knowledge on already existing technologies that are currently being used by competitors;

Know_new knowledge on new technologies that are not yet being used in practice.

Table 2b. Perceived knowledge on available technologies: firms' characteristics, simple ordered probit

\begin{tabular}{|c|c|c|c|c|c|c|c|}
\hline KNOWLEDGE & $\begin{array}{l}\text { Sample } \\
\text { average }\end{array}$ & Energy quote & $\begin{array}{l}\text { Investment } \\
\text { quote }\end{array}$ & Profit quote & Size & Competition & $\begin{array}{c}\text { International } \\
\text { orientation }\end{array}$ \\
\hline Know_exist & 3.18 & +0.34 & $+1.44^{* *}$ & +0.03 & $+0.11^{* *}$ & $+0.25^{*}$ & $+0.20^{* * *}$ \\
\hline Know_new & 2.79 & +0.61 & $+1.23^{* *}$ & -0.04 & $+0.10^{* *}$ & $+0.29^{* *}$ & $+0.27^{* * * *}$ \\
\hline
\end{tabular}

$* / * * / * * *$ indicates significance at the $0.1 / 0.05 / 0.01$ level (two-sided t-test) in simple ordered probit regression;

Bold estimates indicate that the sign of a significant parameter in the simple regression is 'robust': no significant parameter of the opposite sign is found for this variable in multiple regressions

Several results shown in the tables are noteworthy. First, the firms' knowledge on both new and already employed technologies is particularly high in the chemical industry, while it is low in the metal and food industry. Secondly, such strategic knowledge is especially high in large firms that invest heavily and are faced with strong competition. This last result is particularly interesting, as it reveals that there is some truth in the argument that competition indeed functions as an incentive generating mechanism, forcing firms to obtain strategic information. Although it has to be acknowledged that the causality might run both ways, also the positive correlation between knowledge and total investments is conform our expectation. These results are in clear contrast with Gillissen et al. (1995), who conclude that the information gap

\footnotetext{
3 Ordered probit estimation properly takes account of the fact that the independent variable can take on only discrete values. The interpretation of the coefficients in the Table $2 b$, however, is difficult (this is a notorious problem with ordered probit estimates; see for example Greene, 1997). This is exactly the reason for using OLS when considering the sector dummies: the estimated parameters can easily be interpreted as the sector-specific difference in average score (compared to the entire sample). In the text, when discussing ordered probit results, we restrict the analysis to the sign and significance of the obtained parameter values. More detailed information on the estimates is available upon request from the authors.
} 
is largely sectorally determined. Our analysis reveals that the information gap is particularly large in small firms facing limited competition and spending relatively little on investments. There is some sectoral effect in that firms with these characteristics are over-represented in the food and basic metals industry, and underrepresented in the chemical industry. Our results are largely in line with Gruber and Brand (1991) who performed a study on, among others, knowledge on technologies in German small and medium-sized firms.

Although knowledge about and expected profitability of available technologies are necessary conditions for implementation of new technologies, they are not sufficient. There may be a host of barriers that still prevent the firm from (immediately) investing and result in an 'energy gap'. The optimal timing of the adoption of new technologies is an important issue in the economic literature (see, e.g., Farrell and Saloner, 1986; Choi, 1994; Koski and Nijkamp, 1998), especially in the presence of so called forward and backward externalities. The estimation of the expected installed base of adopters of a new technology and the costs and benefits of waiting for a new technology are a major source of uncertainty. Figure 2 shows the relative importance of barriers to adoption. Scores range from 1 (barrier is completely unimportant) to 5 (barrier is very important). The responses shown here concern technologies about which firms had indicated earlier in the survey that they are aware of their existence, that were considered as being profitable, but that were still not implemented as yet. Three main categories of barriers can be distinguished: general barriers related to the overall decisionmaking of firms with respect to production and investment, financing constraints, and barriers that are related to uncertainty about, for example, future technology, prices and policy developments, and the quality of the new technology.

\section{< Insert Figure 2 around here >}

The most important barrier for firms is the existence of other investment opportunities that are considered more promising or important. Especially if financial or organisational constraints play a role, investments in energy saving are likely to be pushed aside in favour of other, more attractive, investments. Also resistance to replace existing machinery turns out to be an important obstacle. This suggests that in the future, considerable improvements can still be made, once old machinery is going to be replaced due to obsolescence. Also, the relatively 
small amount of money spent on energy is acting as a barrier to investing in new technology. Apparently, the costs of acquiring information and incorporating the new technologies within the firm often exceed the expected savings on the energy bill. Lack of financial means to finance the investments turns out to be a problem of relatively minor importance. Uncertainty is of intermediate importance. An important fear that firms have is that future technologies will be significantly better or cheaper. This generally induces a postponement of investments. Part of the uncertainty is also related to policy and results from uncertainty about future subsidies or environmental requirements. Figure 3 shows that cost savings due to lower energy use are the most important driving force for investing in energy saving technologies. Policy measures like subsidies and fiscal arrangements may be supportive in steering investments towards higher energy efficiency.

\section{< Insert Figure 3 around here >}

The next step in our analysis was to test whether the barriers to investing in energy-efficient technologies differed between sectors (Table 3a), and whether these barriers differed according to firm characteristics (Table $3 b$ ). The estimation technique used in Table $3 a$ is comparable to the technique underlying Table $2 \mathrm{a}$, while the estimation technique employed in Table $3 b$ is comparable to the one in Table $2 b$.

It is evident from Table 3a that there are only a few barriers that play a systematically different role in different sectors. The only two sectors that stand out somewhat are the basic metals sector and horticulture. The general barriers play a relatively important role in the sector producing basic metals. It appears from the results that current installations are thought to be sufficiently efficient from an energy point of view and that the willingness to replace them is (therefore) fairly low. An opposite pattern can be found in horticulture. In this sector, current installations are thought to be insufficiently energy efficient and there are no problems in that current installations initially have to be replaced which can be explained from the extremely high energy intensity of this sectors. Problems do exist in this sector however, in that organisational constraints prevent the introduction of new technologies. The importance of organisational factors for understanding the energy efficiency paradox has been stressed by, for example, DeCanio (1993). 
The extent to which barriers to invest to invest in energy saving technologies vary with firm characteristics is described in Table 3b. As one would expect, the general barriers play less of an important role in energy intensive firms (except for the organisational barriers, which is strongly driven by the fact that horticulture is energy intensive and faced with organisational barriers). A surprising result is that weight attached to barriers by profit making firms is relatively large. Especially the barriers associated with uncertainty seem to refrain profit making firms from investing. A potential explanation for this result is that the profitable firms in our sample tend to be the energy extensive firms. As we saw before, these firms attach more weight to the various potential barriers to invest in energy saving technology, which makes clearly some sense. Another explanation may be that more profitable firms do consider uncertainty more explicitly when making investment decisions. Economically better management would then jointly explain both the high profitability and the consideration of uncertainty. A similar argument could explain why these firms less often state that energy efficiency is less important per se.

Similarly surprising is the fact that large firms attach a relatively large weight to general barriers (except for organisational barriers, which may again reflect the fact that horticulture is characterised by organisational barriers and relatively small firms). Finally, competitive forces turn out to affect the importance of reasons for not adopting energy saving technologies. In particular, more competitive firms tend to be faced relatively stringently with organisational barriers and also tend to abstain from technology adoption due to various sources of uncertainty (especially the fact that technologies may become cheaper in the future which makes it advantageous to wait). 
Table 3a. Barriers for implementation of energy saving technologies: sectors, OLS

\begin{tabular}{l|cccccccc}
\hline BARRIERS & $\begin{array}{c}\text { Sample } \\
\text { average }\end{array}$ & CHEM & BASEMET & MET & FOOD & PAPER & HORT & REST \\
\hline GENERAL & & & & & & & & \\
OthIm & 3.74 & -0.10 & +0.48 & -0.03 & +0.59 & -0.24 & -0.44 & -0.34 \\
AftRe & 3.51 & +0.09 & $+0.71^{*}$ & -0.34 & -0.01 & -1.01 & $-0.61^{*}$ & +0.74 \\
EnCo & 3.35 & +0.35 & +0.03 & +0.08 & +0.15 & -0.35 & -0.17 & -0.55 \\
LoPrio & 3.08 & +0.10 & +0.17 & -0.23 & +0.25 & -1.08 & -0.31 & +0.52 \\
CurEf & 3.00 & -0.20 & $+0.63^{*}$ & 0.00 & $-0.67^{*}$ & -0.50 & -0.08 & +0.75 \\
NowIm & 2.96 & -0.16 & -0.33 & -0.79 & +0.24 & +0.04 & +0.29 & +1.38 \\
Organ & 2.83 & -0.20 & +0.29 & -0.33 & -0.67 & -0.33 & $+0.87^{* *}$ & -0.43 \\
FINANCE & & & & & & & & $-1.16^{*}$ \\
IntBu & 2.66 & -0.10 & +0.45 & +0.63 & +0.17 & +0.34 & -0.46 & -0.62 \\
ExtBu & 2.22 & -0.22 & -0.34 & +0.62 & +0.58 & +0.28 & +0.08 & +0.09 \\
UNCERTAINTY & & & & & & & & +0.09 \\
UnQua & 2.71 & -0.31 & +0.67 & -0.38 & -0.14 & -0.21 & +0.09 & +0.09 \\
Sub & 2.54 & -0.14 & -0.17 & -0.38 & -0.11 & $+1.46^{*}$ & -0.04 & +0.66 \\
Cheap & 2.48 & +0.02 & +0.27 & -0.48 & +0.38 & -0.48 & +0.22 & -0.68 \\
Overv & 2.38 & -0.48 & 0.00 & +0.20 & +0.29 & +0.63 & -0.08 & +0.23 \\
Wait & 2.35 & -0.45 & +0.27 & -0.52 & +0.36 & -0.35 & +0.35 & +0.05 \\
Norms & 2.33 & +0.07 & +0.17 & -0.73 & +0.51 & +0.17 & -0.03 & -0.33 \\
\hline
\end{tabular}

$* / * * / * * *$ indicates significance at the $0.1 / 0.05 / 0.01$ level (two-sided t-test) in OLS regression

\section{VARIABLE DESCRIPTIONS}

OthIm Other investments more important

AftRe Technology can only be implemented after existing technology has been replaced

EnCo Energy costs are not sufficiently important

LoPrio Energy efficiency has low priority

CurEf Current installations are sufficiently efficient

NowIm Currently introducing the specific technology

Organ Difficult to implement due to internal organisation

IntBu Internal constraints on the budget

ExtBu Problems with external financing

UnQua Uncertainty regarding the quality

Sub Better to wait for subsidies

Cheap Technology will become cheaper

Overv No good overview of existing technologies

Wait Better to await experience of colleagues

Norms Maybe new technology will not satisfy future standards 
Table 3b. Barriers for implementation of energy saving technologies: firms' characteristics, simple ordered probit

\begin{tabular}{|c|c|c|c|c|c|c|c|}
\hline BARRIERS & $\begin{array}{l}\text { Sample } \\
\text { average }\end{array}$ & $\begin{array}{c}\text { Energy } \\
\text { quote }\end{array}$ & $\begin{array}{c}\text { Investment } \\
\text { quote }\end{array}$ & Profit quote & Size & Competition & $\begin{array}{c}\text { International } \\
\text { orientation }\end{array}$ \\
\hline \multicolumn{8}{|l|}{ GENERAL } \\
\hline OthIm & 3.74 & +0.32 & -0.65 & $-7.65^{* * *}$ & $+0.14^{*}$ & +0.24 & +0.01 \\
\hline AftRe & 3.51 & $-1.17^{*}$ & +0.14 & +2.35 & +0.08 & +0.05 & +0.01 \\
\hline EnCo & 3.35 & $-1.21^{*}$ & -0.02 & +1.10 & +0.04 & -0.13 & +0.14 \\
\hline LoPrio & 3.08 & -0.84 & +1.17 & +0.53 & +0.03 & -0.04 & -0.04 \\
\hline CurEf & 3.00 & -0.73 & +0.54 & +2.25 & +0.06 & -0.26 & +0.15 \\
\hline NowIm & 2.96 & -0.37 & +0.74 & +3.26 & +0.04 & +0.13 & -0.01 \\
\hline Organ & 2.83 & $+1.45^{*}$ & +0.65 & -0.46 & -0.12 & $+0.63^{* *}$ & -0.08 \\
\hline \multicolumn{8}{|l|}{ FINANCE } \\
\hline IntBu & 2.66 & -0.60 & -0.47 & +0.28 & $+0.17^{* *}$ & +0.11 & +0.15 \\
\hline $\mathrm{ExtBu}$ & 2.22 & -0.43 & -1.17 & +0.27 & -0.01 & -0.24 & -0.09 \\
\hline \multicolumn{8}{|l|}{ UNCERTAINTY } \\
\hline UnQua & 2.71 & -0.73 & +0.39 & +2.35 & -0.05 & +0.18 & -0.09 \\
\hline Sub & 2.54 & -1.31 & +0.10 & $+7.51^{* * *}$ & -0.03 & +0.22 & +0.16 \\
\hline Cheap & 2.48 & -0.80 & -0.93 & $+4.02^{* *}$ & -0.00 & $+0.60^{* *}$ & +0.01 \\
\hline Overv & 2.38 & -0.96 & -0.39 & +1.09 & -0.04 & -0.17 & -0.09 \\
\hline Wait & 2.35 & -0.65 & -0.47 & $+8.02^{* * *}$ & -0.03 & $+0.47^{*}$ & +0.01 \\
\hline Norms & 2.33 & -1.91 & +0.12 & +0.58 & +0.03 & +0.09 & -0.04 \\
\hline
\end{tabular}

$* / * * / * * *$ indicates significance at the $0.1 / 0.05 / 0.01$ level (two-sided t-test) in simple ordered probit regression; Bold estimates indicate that sign of significant parameter in simple regression is 'robust': no significant parameter of the opposite sign is found for this variable in multiple regressions

\section{Responsiveness to policy changes}

Having discussed the investment behaviour of firms, we will now turn to a discussion of policy issues. In this section, we will discuss how firm state they would respond to the introduction of an energy tax. In particular, we asked firms to state the likelihood that they would react to an increase in energy taxes on a national level, with no rebatements of the revenues generated, by: lowering or increasing production, changing the production mix towards less energy intensive goods, charging customers with the increased costs, introduce and adopt energy saving technologies, develop energy saving technologies, change to other energy sources (wind or solar energy), leave the market by either shutting down or evade the tax by moving abroad, or do nothing and accept the loss. In the next section, we will consider the related question on the extent to which firms find particular policies acceptable. 
Figure 4 gives some insight into the expected reactions (under the assumption of no rebatements). Firms are likely to react by (faster) introduction of energy saving technologies or charging the customers with the additional costs. Also changes in the product mix are considered as a useful option. Clearly, taxes will not be ineffective; the 'no reaction' option received the lowest score.

\section{< Insert Figure 4 around here >}

Tables $4 \mathrm{a}$ and $4 \mathrm{~b}$ yield insights into whether the reactions on an energy tax vary with firm and sector characteristics.

Table 4a. Reactions on introduction of energy tax on national level with no rebatement: sectors, OLS

\begin{tabular}{l|cccccccc}
\hline REACTIONS & $\begin{array}{c}\text { Sample } \\
\text { average }\end{array}$ & CHEM & BASEMET & MET & FOOD & PAPER & HORT & REST \\
\hline AltEn & 2.47 & $-0.51^{* *}$ & -0.01 & -0.11 & +0.28 & -0.47 & $+0.39^{*}$ & +0.08 \\
Shut & 2.14 & +0.19 & -0.45 & +0.29 & +0.05 & +0.53 & +0.07 & -0.44 \\
DevET & 2.64 & -0.14 & +0.36 & -0.26 & -0.33 & -0.22 & +0.29 & +0.06 \\
ImpET & 3.49 & -0.31 & -0.07 & +0.05 & +0.32 & +0.08 & +0.15 & -0.14 \\
Price & 3.19 & -0.41 & +0.35 & $+0.67^{*}$ & +0.34 & +0.52 & $-0.88^{* * *}$ & +0.46 \\
PrMix & 2.55 & -0.09 & +0.07 & -0.19 & +0.20 & -0.12 & +0.28 & -0.35 \\
Nothing & 1.56 & +0.05 & -0.02 & -0.28 & -0.06 & -0.13 & +0.14 & +0.04 \\
IncPr & 2.39 & $-0.62^{* * *}$ & -0.00 & -0.31 & +0.02 & -0.10 & $+0.51^{* *}$ & +0.16 \\
DecPr & 2.06 & $+0.65^{* * *}$ & +0.10 & -0.44 & -0.18 & +0.44 & -0.16 & -0.34 \\
Migr & 2.60 & $+0.58^{* *}$ & -0.60 & -0.03 & $-0.60^{*}$ & $+1.40^{* *}$ & +0.23 & $-0.55^{*}$ \\
\hline
\end{tabular}

$* / * * / * * *$ indicates significance at the $0.1 / 0.05 / 0.01$ level (two-sided t-test) in OLS regression

\section{VARIABLE DESCRIPTOINS}

AltEn Employ other sources of energy;

Shut Shutting down;

DevET Own development of energy saving technologies;

ImpET Introduce energy saving technologies;

Price Increase prices of final products;

PrMix Start producing a less energy intensive product mix;

Nothing No reaction and incur the loss;

IncPr Increase production;

DecPr Decrease production;

Migr Move (parts of) firm to foreign country.

Table $4 \mathrm{a}$ reveals that the reactions on the introduction of an energy tax are significantly different from the average reaction in the chemical sector and the horticulture. More 
specifically, the employment of alternative energy sources is no viable alternative for the chemical sector, while it certainly is in horticulture. There is a strong tendency in the chemical sector to either decrease production in reaction to the introduction of an energy tax or to evade the tax by moving abroad. In horticulture, charging customers with the costs is no alternative, which can be understood from the fact that firms in this sector are strong price takers, prices being determined on the auction. This price-taking behaviour in the horticulture is further illustrated by the fact that especially in this sector, firms are more strongly inclined to increase rather than decrease their production after imposition of a tax. For a practical pricetaker, a tax means that the profit margin decreases, and a larger turnover is necessary to cover fixed costs. ${ }^{4}$ The alternative of moving abroad is also strongly considered in the paper industry. This alternative is not seriously considered by the food industry and the machinery and textiles, which can be understood from the lack of external competitors (see Table 1 and Table 4b). ${ }^{5}$

The results in Table $4 \mathrm{~b}$ reveal that the responsiveness to an increase in energy taxes is particularly high in competitive industries. ${ }^{6}$ The threats from competitors clearly force firms in these industries to react, and the more so the stronger the international orientation. It is interesting to note that more profitable firms have a low tendency to move abroad. This may be explained from the fact that this (probably more drastic) response is not considered necessary when a firm is currently profitable. A related reason could be that current

\footnotetext{
4 The result that a production increase is, in general, considered a more appropriate response to an energy tax than a production decrease seems at odds with textbook models of a firm's response to environmental taxation (e.g., Baumol and Oates, 1988). It could reflect that firms anticipate a larger equilibrium production level, due to other firms leaving the market. A less academic explanation would be the one given in the main text: firms would have a certain target profit level, and will try to sell more after imposition of a tax. This would reflect that firms consciously or unconsciously assume that their average variable costs are constant, and do not consider the fact that higher sales with a given demand curve require lower prices. It would validate the 'folkloristic claims' that firms do not think and act marginally.
}

5 It is interesting to confront the sectoral dependency of the migration-response with the study by van Beers and van den Bergh (1997). They show that the reduction in exports as a consequence of stricter environmental policies is stronger in non-resource based industries than in resource based industries. The fact that the firms that argue to likely react by migrating are located in industries with many foreign competitors may be seen as evidence that these firms are not primarily based in the Netherlands for reasons of resource availability and may thus be seen as an explanation for the fact that especially these firms argue to react by migrating.

6 Results on the responsiveness to international increases in energy prices, national energy taxes with rebatements, and the imposition of stricter standards are also available. 
profitability could partly be explained from a relatively favourable current location, where a firm, for instance, benefits from a successful exploitation of local comparative advantages (labour markets, accessibility, and so forth).

Finally, it is noteworthy that that especially firms with a relatively strong international orientation are hesitant to simply shift the burden from the national energy tax to their customers. This is also conform our prior expectation.

Table 4b. Reactions on introduction of energy tax on national level with no rebatement: firms' characteristics, simple ordered probit

\begin{tabular}{l|ccccccc}
\hline REACTIONS & $\begin{array}{c}\text { Sample } \\
\text { average }\end{array}$ & $\begin{array}{c}\text { Energy } \\
\text { quote }\end{array}$ & $\begin{array}{c}\text { Investment } \\
\text { quote }\end{array}$ & Profit quote & Size & $\begin{array}{c}\text { Competition } \\
\text { International } \\
\text { orientation }\end{array}$ \\
\hline AltEn & 2.47 & +0.15 & -0.48 & +0.76 & -0.04 & +0.07 & -0.06 \\
Shut & 2.14 & +0.29 & -0.11 & -0.02 & +0.03 & $\mathbf{+ 0 . 2 8}^{*}$ & +0.10 \\
DevET & 2.64 & +0.02 & +0.36 & +0.07 & -0.03 & +0.10 & +0.08 \\
ImpET & 3.49 & -0.15 & +0.56 & +0.19 & -0.02 & +0.04 & -0.08 \\
Price & 3.19 & $\mathbf{- 1 . 9 0}$ & -0.56 & +0.11 & -0.05 & -0.09 & $\mathbf{- 0 . 2 3}^{* * * *}$ \\
PrMix & 2.55 & +0.19 & -0.06 & +0.09 & -0.01 & +0.05 & -0.05 \\
Nothing & 1.56 & +0.53 & NA & NA & NA & NA & NA \\
IncPr & 2.39 & +0.59 & +0.81 & -0.13 & $\mathbf{- 0 . 1 5}^{* * *}$ & -0.17 & -0.10 \\
DecPr & 2.06 & +0.31 & -0.03 & -0.03 & $\mathbf{+ 0 . 1 0}^{* *}$ & $\mathbf{+ 0 . 3 7 ^ { * * }}$ & $\mathbf{+ 0 . 1 5}^{*}$ \\
Migr & 2.60 & +0.37 & -0.60 & $\mathbf{2 . 9 4}^{* *}$ & $\mathbf{+ 0 . 2 1}^{* * *}$ & $\mathbf{+ 0 . 3 8}^{* *}$ & $\mathbf{+ 0 . 3 0}^{* * * *}$ \\
\hline
\end{tabular}

$* / * * / * * *$ indicates significance at the $0.1 / 0.05 / 0.01$ level (two-sided t-test) in simple ordered probit regression; Bold estimates indicate that the sign of a significant parameter in simple regression is 'robust': no significant parameter of the opposite sign is found for this variable in multiple regressions

\section{Attitudes Towards Environmental Policy}

When barriers are existing and restrain firms from investing, there is a potential role for the government. The barriers found in our survey may provide a justification for the active role the Dutch government has recently played in coping with environmental problems, and the type of actions undertaken. Acceptability and support for the various policy measures are a prerequisite for their success. We have therefore asked firms on their opinion about various types of environmental policy. Figure 5 summarises the main findings. As one would expect, subsidies are preferred to taxes. Voluntary agreements are also appreciated, in contrast to standards. These results reveal that firms want to maximise the freedom in deciding how to 
cope with the desire of the government to increase the quality of the environment. Obviously, the acceptance of energy taxes strongly increases if measures are taken that minimise the adverse effects on the firms' competitive position and profitability. Examples are energy taxes with direct recycling of the tax revenues through lower labour taxes, and energy taxes on a European level. Clearly, it is not the efficiency or effectiveness of energy taxes per se (the effect on relative input prices) that worries firms most, but much more the distributional effect (the money transfer), inducing adverse effects on the competitive position of the firm. This evidence provides rather unambiguous guidelines for improving the acceptability of increasing energy taxes as proposed in the Dutch Environmental Plan (the so called NMP3).

\section{< Insert Figure 5 around here >}

Another issue in energy policy is whether additional policy measures to reduce energy use are acceptable for firms, or only so under certain conditions. The majority of firms indicated to accept government interference, especially when this is taking place in an international setting. This again points at the importance of taking into account and sustaining the competitive position of firms when judging energy policies.

Finally, we return to the question whether the acceptability of energy policies in general and policy measures in particular did vary between sectors and with firm characteristics. The results are summarised in Tables 5a, 5b, 6a, and $6 \mathrm{~b}$. 
Table 5a. Acceptation of energy policies in general: sectors, OLS

\begin{tabular}{l|cccccccc}
\hline ACCEPTATION & $\begin{array}{c}\text { Sample } \\
\text { average }\end{array}$ & CHEM & BASEMET & MET & FOOD & PAPER & HORT & REST \\
\hline Acc & 2.95 & -0.05 & +0.13 & +0.26 & +0.36 & +0.05 & -0.32 & -0.07 \\
AccForm & 3.29 & +0.36 & +0.28 & +0.21 & +0.31 & -0.15 & -0.29 & -0.51 \\
DaccF & 0.48 & +0.40 & +0.24 & -0.35 & -0.18 & -0.33 & +0.00 & -0.14 \\
AccSec & 3.55 & $+0.40^{*}$ & +0.31 & -0.17 & +0.45 & -0.17 & -0.20 & $-0.65^{* *}$ \\
DaccS & 0.69 & $+0.44^{*}$ & +0.31 & $-0.69^{*}$ & -0.02 & -0.44 & +0.11 & -0.29 \\
AccAbr & 3.74 & +0.26 & +0.12 & -0.18 & +0.17 & -0.11 & +0.01 & $-0.63^{*}$ \\
DaccA & 0.94 & +0.43 & +0.06 & -0.61 & -0.24 & -0.44 & +0.24 & -0.28 \\
\hline
\end{tabular}

$* / * * / * * *$ indicates significance at the $0.1 / 0.05 / 0.01$ level (two-sided t-test) in OLS regression

\section{VARIABLE DESCRIPTION}

Acc Acceptable in any case;

AccForm Acceptable provided policy is in a particular (unspecified) format;

DaccF Difference between acceptability of policy in particular format and acceptability in any case

AccSec Acceptable provided policy applies to all sectors;

DAccS Difference between acceptability of policy applied in all sectors and acceptability in any case

AccAbr Acceptable provided policy also applies abroad;

DaccA Difference between acceptability of policy applied abroad and acceptability in any case.

Table 6a. Acceptation of specific types of energy policies: sectors, OLS

\begin{tabular}{|c|c|c|c|c|c|c|c|c|}
\hline ACCEPTATION & $\begin{array}{l}\text { Sample } \\
\text { average }\end{array}$ & CHEM & BASEMET & $M E T$ & FOOD & PAPER & HORT & $R E S T$ \\
\hline TaxNL & 2.02 & -0.16 & +0.28 & +0.11 & +0.25 & +0.08 & -0.27 & +0.08 \\
\hline TaxNLR & 3.01 & -0.10 & -0.01 & +0.13 & -0.15 & +0.09 & -0.27 & $+0.58^{* *}$ \\
\hline DtaxNLR & 1.03 & +0.12 & -0.33 & -0.03 & -0.31 & -0.03 & -0.06 & $+0.54^{*}$ \\
\hline TaxEU & 2.90 & +0.02 & +0.03 & +0.17 & -0.15 & +0.40 & -0.28 & +0.21 \\
\hline DtaxEU & 0.89 & +0.20 & -0.27 & +0.04 & -0.26 & +0.31 & -0.05 & +0.06 \\
\hline StanTec & 2.22 & -0.04 & +0.24 & -0.15 & +0.34 & +0.11 & -0.05 & -0.28 \\
\hline StanUse & 2.31 & -0.12 & $+0.46^{*}$ & -0.24 & +0.16 & +0.29 & -0.05 & -0.20 \\
\hline InvSub & 3.43 & +0.21 & +0.03 & +0.17 & +0.13 & +0.13 & $-0.33^{*}$ & -0.03 \\
\hline RDSub & 3.49 & $+0.38^{*}$ & -0.03 & +0.05 & +0.07 & +0.07 & -0.15 & -0.29 \\
\hline Volag & 3.20 & +0.27 & +0.30 & +0.08 & -0.08 & -0.20 & -0.20 & -0.08 \\
\hline
\end{tabular}

$* / * * / * * *$ indicates significance at the $0.1 / 0.05 / 0.01$ level (two-sided t-test) in OLS regression

\section{VARIABLE DESCRIPTION}

TaxNL Acceptability of energy tax in Netherlands;

TaxNLR Acceptability of energy tax in Netherlands with rebatement of tax revenues;

DTaxNLR Difference in acceptability between energy tax in Netherlands with and without rebatement;

TaxEU Acceptability of energy tax on European level;

DTaxEU Difference in acceptability between energy tax in Europe and in Netherlands;

StanTec Acceptability of technology standards;

StanUse Acceptability of emission standards;

InvSub Acceptability of investment subsidies;

RDSub Acceptability of R\&D subsidies;

Volag Acceptability of voluntary agreements. 
We may conclude from Tables 5a and 6a that the acceptability of policy measures is relatively high in the chemical sector and the sector producing basic metals. It is evident from Tables $5 \mathrm{~b}$ and $6 \mathrm{~b}$ that this result is likely to be driven by the fact that large internationally operating firms that face strong competition make up these sectors. Acceptability is fairly low in the horticulture, machinery and textile industry, which have characteristics exactly opposite to those of the chemical and basic metals industry. A surprising result is that the acceptability of some policy measures is low for profitable firms. These firms especially oppose against subsidies and voluntary agreements, which may be seen as measures that put relatively weak competitors in a comparatively advantageous position.

Table 5b. Acceptation of energy policies in general: firms' characteristics, simple ordered probit

\begin{tabular}{|c|c|c|c|c|c|c|c|}
\hline ACCEPTATION & $\begin{array}{l}\text { Sample } \\
\text { average }\end{array}$ & Energy quote & $\begin{array}{c}\text { Investment } \\
\text { quote }\end{array}$ & Profit quote & Size & Competition & $\begin{array}{c}\text { Internationa } \\
\text { orientation }\end{array}$ \\
\hline $\mathrm{Acc}$ & 2.95 & -0.25 & -0.78 & -0.03 & +0.06 & +0.14 & -0.05 \\
\hline AccForm & 3.29 & +0.10 & -0.51 & -0.09 & $+0.14^{* *}$ & $+0.33^{*}$ & -0.02 \\
\hline DaccF & 0.48 & +0.33 & +0.20 & -0.07 & $+0.12^{* *}$ & $+0.32^{*}$ & +0.09 \\
\hline AccSec & 3.55 & +0.18 & -0.51 & -0.06 & $+0.16^{* * *}$ & +0.28 & +0.01 \\
\hline DaccS & 0.69 & +0.38 & +0.34 & -0.06 & $+0.14^{* *}$ & $+0.41^{* *}$ & +0.12 \\
\hline AccAbr & 3.74 & +0.01 & -0.24 & $-2.44^{*}$ & $+0.17^{* * *}$ & $+0.51^{* * *}$ & $+0.18^{* *}$ \\
\hline DaccA & 0.94 & +0.23 & +0.17 & -0.03 & $+0.14^{* * *}$ & $+0.52^{* * *}$ & $+0.24^{* * *}$ \\
\hline
\end{tabular}

$* / * * / * * *$ indicates significance at the $0.1 / 0.05 / 0.01$ level (two-sided t-test) in simple ordered probit regression; Bold estimates indicate that sign of a significant parameter in simple regression is 'robust': no significant parameter of the opposite sign is found for this variable in multiple regressions

Table 6b. Acceptation of specific types of energy policies: firms' characteristics, simple ordered

\begin{tabular}{|c|c|c|c|c|c|c|c|}
\hline ACCEPTATION & $\begin{array}{c}\text { Sample } \\
\text { average }\end{array}$ & Energy quote & $\begin{array}{c}\text { Investment } \\
\text { quote }\end{array}$ & Profit quote & Size & Competition & $\begin{array}{c}\text { International } \\
\text { orientation }\end{array}$ \\
\hline TaxNL & 2.02 & -0.39 & -0.18 & +0.01 & $-0.11^{* *}$ & -0.15 & $-0.15^{*}$ \\
\hline TaxNLR & 3.01 & -0.09 & +0.48 & +0.01 & -0.06 & -0.18 & -0.09 \\
\hline DtaxNLR & 1.03 & +0.27 & +0.55 & -0.01 & +0.04 & -0.06 & +0.03 \\
\hline TaxEU & 2.90 & -0.46 & +0.66 & +0.07 & -0.03 & -0.02 & -0.02 \\
\hline DtaxEU & 0.89 & -0.19 & +0.69 & +0.08 & $+0.08^{*}$ & +0.14 & +0.12 \\
\hline StanTec & 2.22 & +0.45 & -0.13 & -0.15 & $+0.09^{*}$ & -0.06 & +0.11 \\
\hline StanUse & 2.31 & +0.17 & +0.41 & +0.02 & $+0.09^{*}$ & +0.15 & +0.06 \\
\hline InvSub & 3.43 & +0.08 & -0.36 & $-2.47^{* * *}$ & $+0.09^{*}$ & -0.09 & +0.01 \\
\hline RDSub & 3.49 & +0.50 & -0.56 & -0.12 & $+0.18^{* * * *}$ & +0.05 & $+0.13^{*}$ \\
\hline Volag & 3.20 & +0.37 & -0.11 & $-3.67^{* * *}$ & $+0.26^{* * *}$ & +0.02 & $+0.15^{* *}$ \\
\hline
\end{tabular}

$* / * * / * * *$ indicates significance at the $0.1 / 0.05 / 0.01$ level (two-sided t-test) in simple ordered probit regression; Bold estimates indicate that sign of a significant parameter in simple regression is 'robust': no significant parameter of the opposite sign is found for this variable in multiple regressions 


\section{Conclusions}

This paper has presented and interpreted the results of a survey among Dutch firms carried out in the context of a nation-wide environmental program on 'Policy Instruments for Energy Efficiency Improvement'. The survey has provided us with a unique data set that to obtain a better understanding of how investment decisions are being made, how they vary between heterogeneous firms and sectors, and how they can potentially be influenced by environmental policy. These insights are important for the development of efficient and acceptable environmental policies in a small open economy like the Dutch one.

From our investigation, we may conclude that energy saving increasingly becomes an integrated and normal part of the business operation of Dutch firms. The economic potential for cost savings is the most important driving force behind investment decisions. The existence of other, more attractive, investment opportunities and the uncertainty about potential declines in the price or improvements in the quality of new technologies are important impediments for not (yet) investing in energy saving technologies. A more strict environmental policy is acceptable for many firms, provided that this measure will not negatively affect profitability and the competitive position of firms. Taxes, especially with 'recycling' programmes and carried out in a wider international context, are even preferred by to detailed policy guidelines on how to achieve policy goals.

\section{References}

Adar, Z., and J.M. Griffin (1976): 'Uncertainty and the Choice of Pollution Control Instruments', Journal of Environmental Economics and Management, 3, pp. 178-188.

Baumol, W.J., and W.E. Oates (1988): The Theory of Environmental Policy, second edition, Cambridge University Press, Cambridge, MA.

Beers, C. van and C.J.M. van den Bergh (1997): 'An Empirical Multi-Country Analysis of the Impact of Environmental Regulations on Foreign Trade Flows', Kyklos, 50, pp. 29-46.

Choi, J.P. (1994): 'Irreversible Choice of Uncertain Technologies with Network Externalities', Rand Journal of Economics, 25, pp. 382-401. 
DeCanio, S.J. (1993): 'Barriers within Firms to Energy-Efficient Investments', Energy Policy, september 1993, pp. 906-914.

Dixit, A.K. and R.S. Pindyck (1994): Investment under uncertainty, Princeton University Press, Princeton.

Farrell, J., and G. Saloner (1986): 'Installed Base and Compatibility: Innovation, Product Preannouncements, and Predation', American Economic Review, 76, pp. 940-955.

Gillissen, M., H. Opschoor, J. Farla, and K. Blok (1995): Energy Conservation and Investment Behaviour of Firms, Economic and Social Institute, Amsterdam.

Greene, W.H. (1997): Econometric Analysis, third edition, Prentice Hall, New York.

Gruber, E. and M. Brand (1991): 'Promoting Energy Conservation in Small and MediumSized Companies', Energy Policy, april 1991, pp. 279-287.

Johnson, B.E. (1994): 'Modeling Energy Technology Choices: Which Investment Analysis Tools are Appropriate?', Energy Policy, 22, pp. 877-883.

Koski, H., and P. Nijkamp (1998): Optimal Timing of Adoption of Network Technologies, Research Memorandum, Department of Spatial Economics, Free University, Amsterdam.

Roberts, M.J., and M. Spence (1976): 'Effluent Charges and Licenses under Uncertainty', Journal of Public Economics, 5, pp. 193-208.

Tietenberg, T., K. Button and P. Nijkamp (eds.) (1999), Environmental Instruments and Institutions, Edward Elgar, Cheltenham, UK.

Velthuijsen, J.W. (1993): 'Incentives for Investments in Energy Efficiency, an Econometric Evaluation and Policy Implications', Environment and Resource Economics, 3, pp. 2339. 


\section{Appendix. Description of Variables}

ACC

ACCABR

ACCFORM

ACCSEC

AFTRE

ALTEN

BASEMET

CHEAP

CHEM

COMP

COMPIN

CUREF

DACCA

DACCF

DACCS

DECPR

DEVET

DTAXEU

DTAXNLR

ENCO

ENQ

EXTBU

FOOD

HORT

IMPET

INCPR

INQ

INTBU

INVSUB

KNOW_EXIST

KNOW_NEW

LABOUR

LLABOUR

LOPRIO

MET

MIGR

NORMS

NOTHING
Energy policies acceptable in any case

Energy policies acceptable provided it also applies abroad

Energy policies acceptable provided it is in a particular (unspecified) format

Energy policy acceptable provided it applies to all sectors

No adoption because technology can only be implemented after existing technology has been replaced

React on energy tax by employing other sources of energy

Basic metals industry

No adoption because technology will become cheaper

Chemical industry

Degree of competition on sales market ( $1=$ limited, $2=$ average, and $3=$ strong);

Location of competitors ( $1=$ mainly in Netherlands, $2=$ less than $50 \%$ abroad, $3=$ more than $50 \%$ abroad, $4=$ virtually all abroad).

No adoption because current installations are sufficiently efficient

Difference between acceptability of policy applied abroad and acceptability in any case

Difference between acceptability of policy in particular format and acceptability in any case

Difference between acceptability of policy applied in all sectors and acceptability in any case

React on energy tax by decreasing production

React on energy tax by own development of energy saving technologies

Difference in acceptability between energy tax in Europe and in Netherlands

Difference in acceptability between energy tax in Netherlands with and without rebatement

Energy costs are not sufficiently important

Energy intensity (expenditures on energy as percentage of sales)

Problems with external financing

food industry

horticulture

Introduce energy saving technologies

Increase production

Investment ratio in 1997 (total investments as percentage of sales)

Internal constraints on the budget

Acceptability of investment subsidies

knowledge on already existing technologies that are currently being used by competitors

knowledge on new technologies that are not yet being used in practice.

Number of employees (sum of full time and part time employees)

Log of number of employees

Energy efficiency has low priority

metal products industry

Move (parts of) firm to foreign country

Maybe new technology will not satisfy future standards

No reaction and incur the loss 
NOWIM

OBSERV

ORGAN

OTHIM

OVERV

PAPER

PRICE

PRMIX

PRQ

RDSUB

REST

SHUT

STANTEC

STANUSE

SUB

TAXEU

TAXNL

TAXNLR

UNQUA

VOLAG

WAIT
Currently introducing the specific technology

Number of observations

Difficult to implement due to internal organisation

Other investments more important

No good overview of existing technologies

paper industry

Increase prices of final products

Start producing a less energy intensive product mix

Profit ratio (total net profits as percentage of sales)

Acceptability of R\&D subsidies

other industries, namely machinery, construction materials and textiles industry.

Shutting down

Acceptability of technology standards

Acceptability of emission standards

Better to wait for subsidies

Acceptability of energy tax on European level

Acceptability of energy tax in Netherlands

Acceptability of energy tax in Netherlands with rebatement of tax revenues

Uncertainty regarding the quality

Acceptability of voluntary agreements

Better to await experience of colleagues 


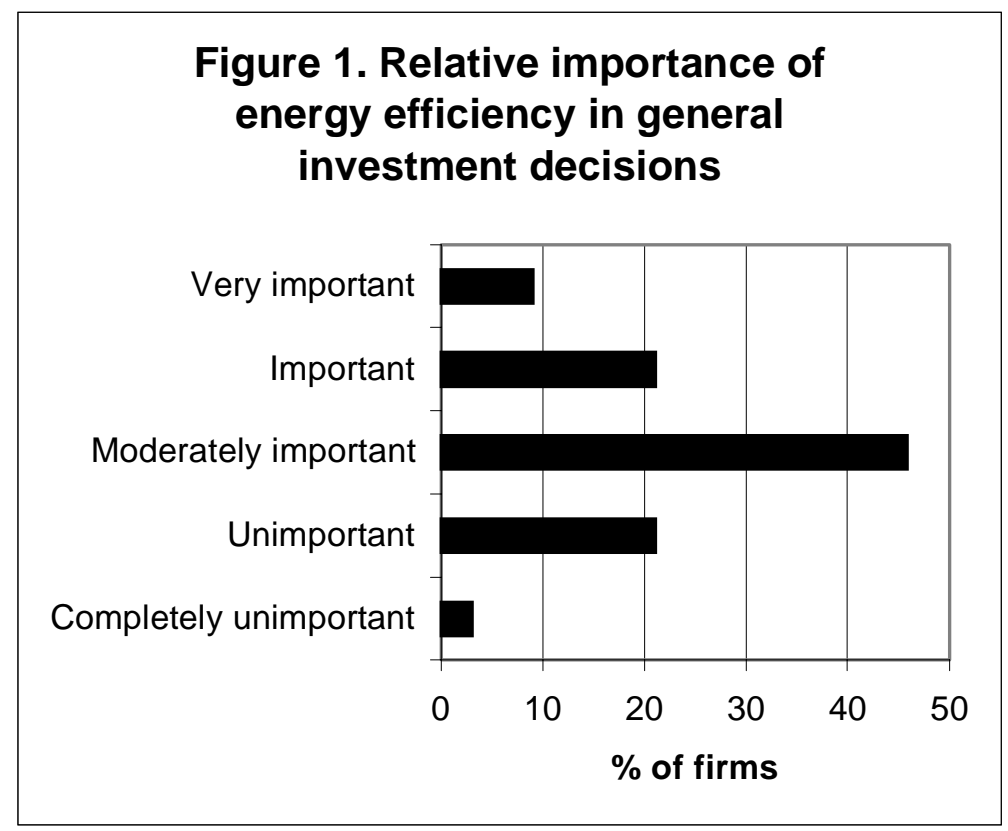




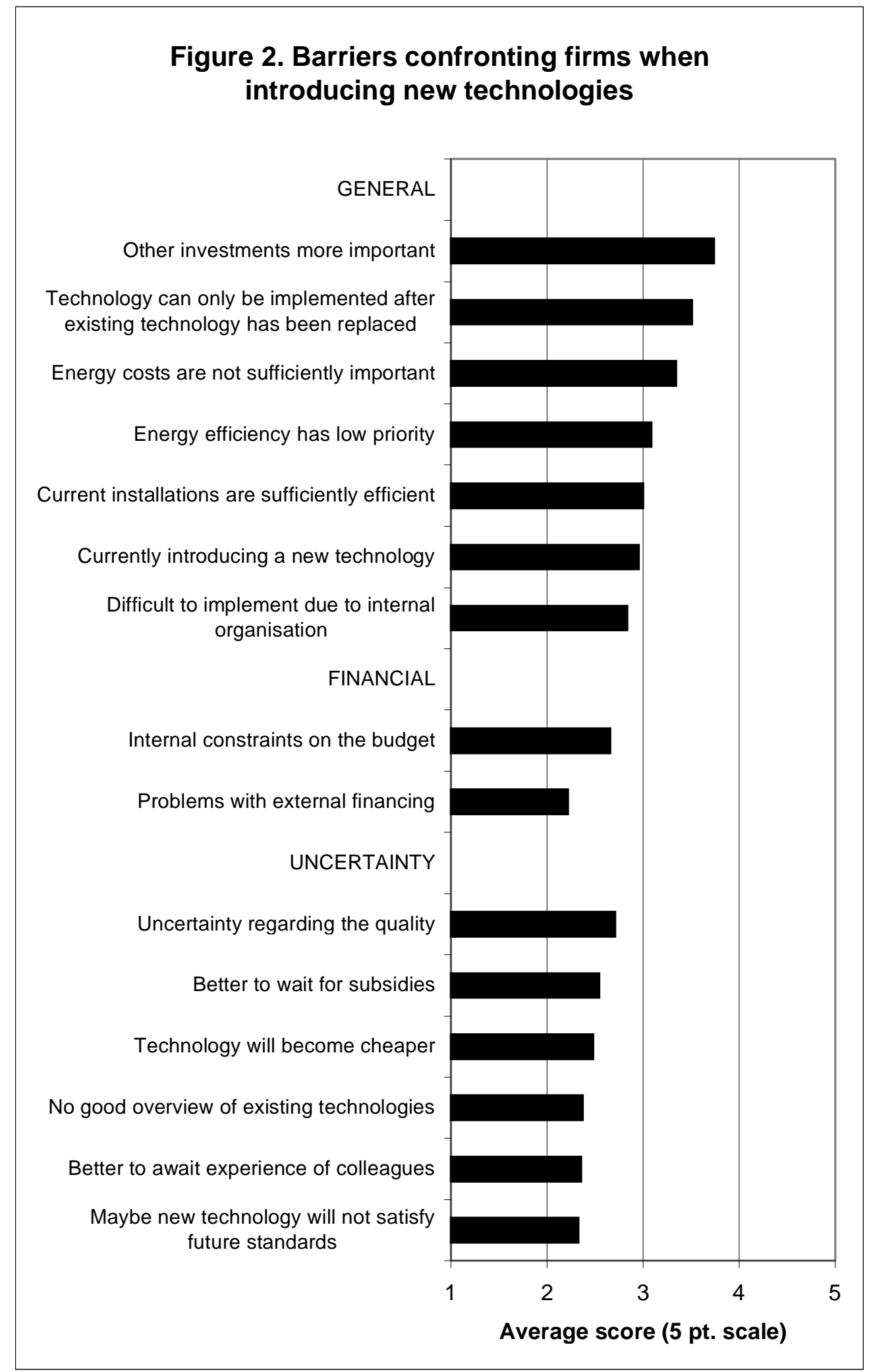




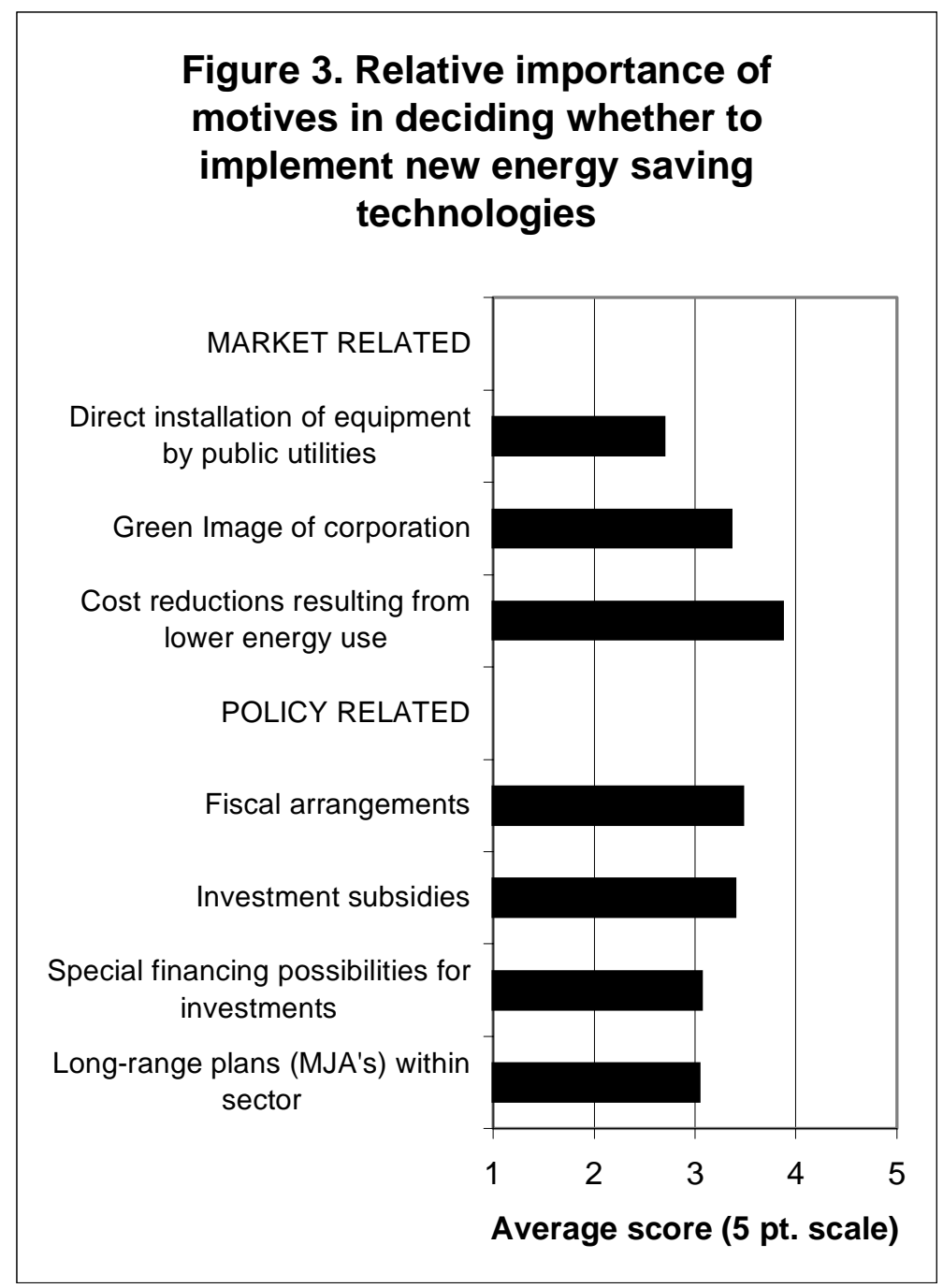




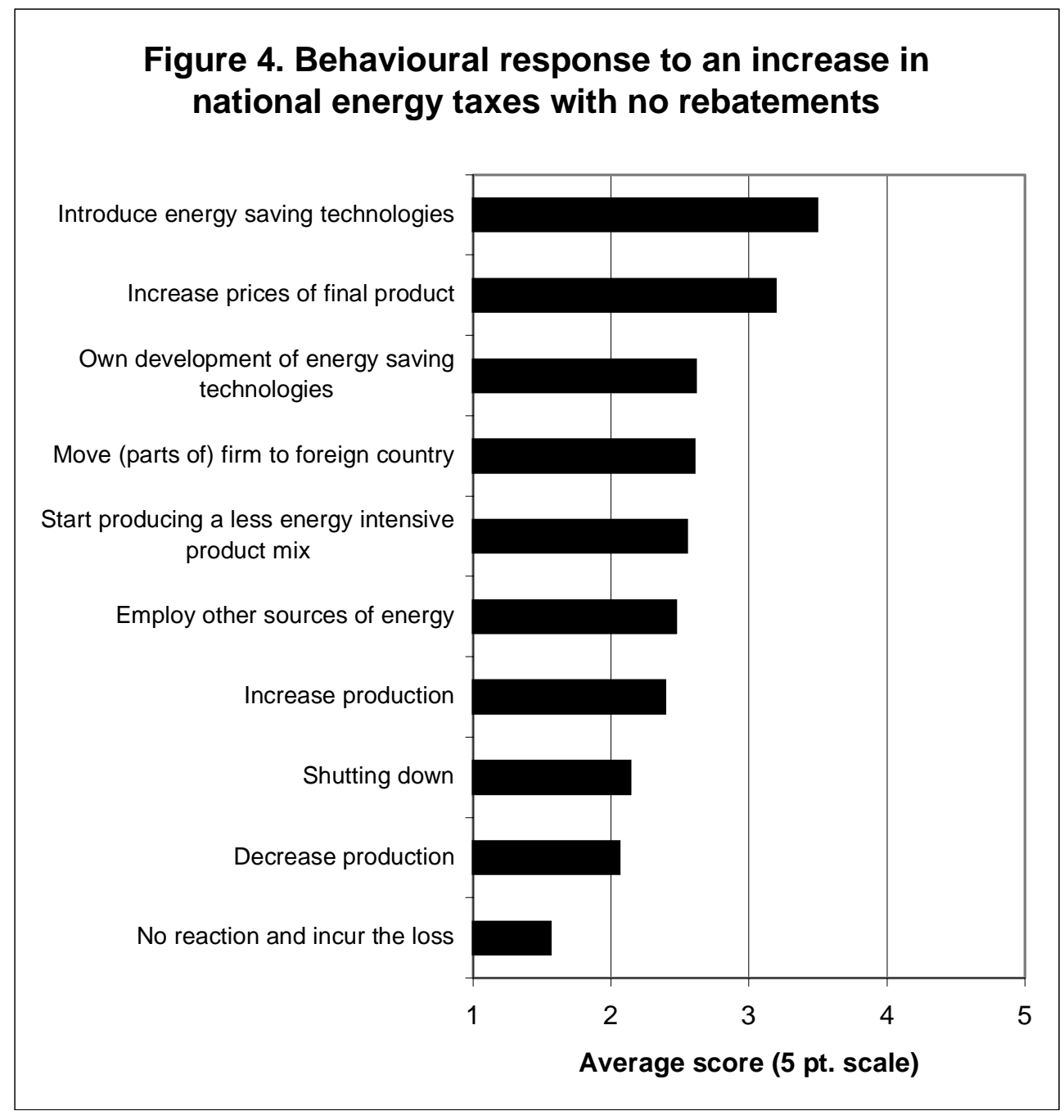




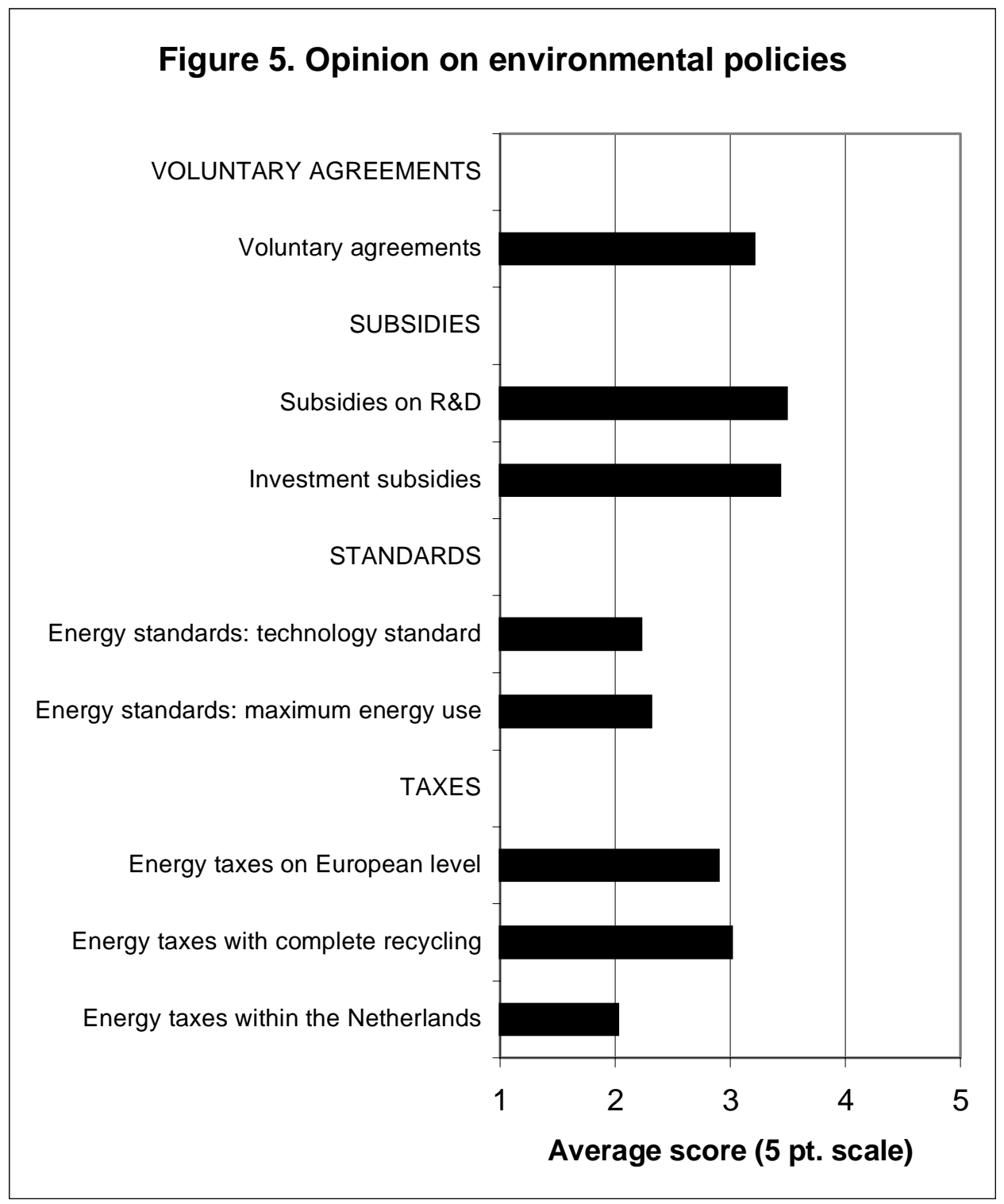

